CDI

18,4

416

Received 20 February 2013

Accepted 4 April 2013

\section{Young and going strong?}

\section{A longitudinal study on occupational health among young employees of different educational levels}

\author{
Jos Akkermans and Veerle Brenninkmeijer \\ Department of Work and Organizational Psychology, Utrecht University, \\ Utrecht, The Netherlands \\ Seth N.J. van den Bossche and Roland W.B. Blonk \\ Department of Work and Employment, TNO, Hoofddorp, The Netherlands, and \\ Wilmar B. Schaufeli \\ Department of Work and Organizational Psychology, Utrecht University, \\ Utrecht, The Netherlands
}

\begin{abstract}
Purpose - The purpose of this paper is to identify job characteristics that determine young employees' wellbeing, health, and performance, and to compare educational groups.

Design/methodology/approach - Using the job demands-resources (JD-R) model and 2-wave longitudinal data $(n=1,284)$, the paper compares employees with a lower educational level with employees with a high educational level.

Findings - Young employees with lower educational level reported fewer job resources (autonomy and social support), more physical demands, less dedication, more emotional exhaustion, and poorer health and performance compared with the highly educated group. Differences were also found between educational groups in the relationships in the JD-R model, most notably a reciprocal association between dedication and performance, and between emotional exhaustion and performance in the group with lower levels of education.
\end{abstract}

Research limitations/implications - The results support the main processes of the JD-R model, supporting its generalizability. However, differences were found between educational groups, implying that the motivational and health impairment processes differ across educational levels.

Practical implications - HR consultants and career counselors may focus especially on increasing job resources and motivation for young employees with lower educational level. Performing well is also important for these young workers to become more dedicated and less exhausted.

Social implications - It is important to recognize and intervene on unique characteristics of different educational groups with regard to wellbeing, health, and performance in order to maintain a healthy and productive young workforce.

Originality/value - For the first time, predictions of the JD-R model are tested among young employees with different educational backgrounds.

Keywords Young employees, JD-R model, Job characteristics, Wellbeing, Education, Occupational health and safety

Paper type Research paper

Career Development International Vol. 18 No. 4, 2013

pp. $416-435$

(C) Emerald Group Publishing Limited 1362-0436

DOI 10.1108/CDI-02-2013-0024
Young employees go through many changes in a relatively brief period of time that may have major consequences for their occupational health and wellbeing: they have to 
make important vocational decisions, adopt new roles, form new relationships, and become more independent from their family (Elfering et al., 2007; Savickas, 1998). These young workers have to go through a socialization process during which they Young and going receive more responsibilities, have to arrange their time in new ways, and have to be more flexible (Ryan, 2001). To make matters worse, young workers have been hit hardest by the worldwide economic crisis that started in 2009 (European Commission, 2012). Faced with these new challenges, the wellbeing of young workers may be determined by other factors compared with older, more experienced employees. strong? Although the increasingly dynamic and complex career challenges are applicable to employees across age groups, research on occupational health and wellbeing thus far has predominantly focused on more experienced employees (e.g. Van der Heijden et al., 2009) and individuals with higher education (e.g. Kuijpers and Meijers, 2012). Because a lack of knowledge seems to exist with respect to young employees, specifically those with lower levels of education, it is important to further investigate factors influencing their wellbeing, health, and performance (see also: Akkermans et al., 2009).

In this study, which is part of an overarching research project that focuses on career development and work-related wellbeing of the young workforce, we will examine factors that can predict wellbeing, health and performance of young employees aged 16-30 years with lower educational levels (i.e. less than 16 years of education; non-college degree), in a two-wave longitudinal sample. A multidirectional perspective is adopted, that is, we will look both at direct and reciprocal relationships over time. Moreover, we will investigate whether motivational and health impairment processes work differently for these young workers, compared with their higher educated counterparts. We will use the job demands-resources model (Demerouti et al., 2001) as our conceptual basis. The JD-R model is an influential model in the field of Work and Organizational Psychology that describes motivational and health impairment processes in the workplace. Based on this model, we examine the associations between job resources, job demands, dedication (a component of work engagement), emotional exhaustion (a component of burnout), general health, and perceived performance.

\section{Young employees with lower levels of education on the labor market}

The many changes and challenges that young employees face when entering the labor market, such as needing to be more flexible, and going through a socialization process at work, can lead to stress and feelings of insecurity (Goodwin and O'Connor, 2007; Koivisto et al., 2007). This may especially be the case for young employees with lower levels of education, as certificate demands are increasing and lower-skilled jobs are also becoming ever more complex, for example because of the growing role of communicative skills and ICT (Nieuwenhuis et al., 2012). These young workers with lower educational levels often face little job security and an extended job search for their first job (Nieuwenhuis et al., 2012). However, at the same time it has been shown that searching for a job can be stressful for young workers (Koivisto et al., 2007), and that they are less engaged in their work (Schaufeli and Bakker, 2004b; Smulders, 2005). Moreover, the differences in quality of work and career opportunities between educational groups are increasing in favor of the higher educated (Raad voor Werk en Inkomen, 2009). Finally, Akkermans et al. (2009) found that young employees with lower levels of education reported fewer job demands and job resources, and a poorer health and performance compared with their higher educated counterparts. In sum, 
CDI

18,4

418 young employees with lower levels of education are confronted with a variety of risk factors with regard to their wellbeing at work, which makes it crucial to gain a better understanding of the factors that can help them remain healthy and motivated.

\section{Determinants of wellbeing, health, and performance at work}

The job demands-resources (JD-R) Model is a heuristic model that includes work-related factors predicting wellbeing and productivity (Demerouti et al., 2001). The JD-R model synthesizes the theoretical insights from several other models, including the conservation of resources theory (COR) (Hobfoll, 1989). The basic assumption is that occupation-specific factors can be classified in job resources and job demands. Job resources are those physical, psychological, social, or organizational aspects of the job that are either functional in achieving work goals, reducing the negative impact of job demands, or stimulating personal growth, learning, and development (Bakker and Demerouti, 2007). Because the presence of sufficient job resources fosters goal accomplishment and personal growth and development, they lead to stronger motivation and dedication at work (Bakker et al., 2003b), thereby setting in motion a motivational process. In this motivational process, job resources are expected to foster work engagement, which is subsequently associated with positive outcomes, such as increased performance and better health (Schaufeli and Bakker, 2004b; Schaufeli et al., 2002).

Job demands are those physical, psychological, social, or organizational aspects of the job that require sustained physical and/or psychological (cognitive and emotional) effort or skills and are therefore associated with certain physical and/or psychological costs (Bakker and Demerouti, 2007). An excessive amount of job demands can lead to energy depletion and thus to exhaustion (Bakker et al., 2003a). In a health impairment process, job demands are associated with exhaustion and strain, which subsequently lead to negative outcomes, such as health problems and sickness absence (Schaufeli and Bakker, 2004b). The motivational and health impairment processes have both received extensive empirical support (e.g. Bakker et al., 2003a; Bakker et al., 2007).

\section{The current study}

In this study we used autonomy, social support of the supervisor, and social support of colleagues as job resources. Furthermore, we used work pressure, emotional workload, and physical workload as job demands. We used these specific job characteristics because they are expected to be relevant for our target group of young workers (Akkermans et al., 2009). Employees need to be increasingly autonomous, but at the same time it is important for them to receive support both from colleagues and supervisors in order to confirm that they are performing well. Furthermore, because young workers have to get used to many challenges and responsibilities, it is relevant to examine the ways in which a high work pressure and emotional workload may affect their wellbeing. In addition, these characteristics are often used in the literature because they apply to a large array of different types of work contexts (Bakker and Demerouti, 2007). Our study is a follow-up of a previous study that also used most of these characteristics (Akkermans et al., 2009). However there are some slight changes. Contrary to the previous study, we did not use task variation as a job resource, as it seemed to act as a job demand. Another difference is that we did use physical workload in this study, as lower skilled jobs are often characterized by more physical work aspects. 
Finally, we used dedication as an indicator of motivation and emotional exhaustion as indicator of strain. Dedication is characterized by a sense of significance, enthusiasm, inspiration, pride, and challenge in one's work (Schaufeli et al., 2002), and emotional exhaustion refers to feelings of being overextended and exhausted by the emotional demands of one's work (Demerouti et al., 2001). By examining dedication and exhaustion, we included two non-overlapping indicators that represent different underlying dimensions of motivation and strain (González-Roma et al., 2006; Schaufeli and Taris, 2005). Our study consisted of two parts. In the first part, we investigated Young and going mean differences between the educational groups (i.e. low versus high) with regard to the current study variables. In the second part of our study we examined potential differences between these groups in motivational and health impairment processes as assumed by the JD-R model.

European labor market studies show increasing differences between educational groups concerning health, sickness absence, and unemployment, whereby employees with lower educational levels report more negative outcomes (European Commission, 2012; Raad voor Werk en Inkomen, 2010). Akkermans et al. (2009) demonstrated that employees with lower levels of education generally experienced fewer job resources, and poorer wellbeing and health compared with their higher educated colleagues. Moreover, lower socioeconomic and educational levels (i.e. blue collar workers) are generally associated with poorer wellbeing and health outcomes (e.g. Adler et al., 1994), and these individuals are less engaged in their work (Schaufeli and Bakker, 2004a). Adler and Ostrove (1999) also stated that educational level by itself is of importance to health outcomes: lower educational levels and lower occupational grades were related to poorer health outcomes at a later age. These findings all indicate that young workers with lower levels of education experience less favorable working conditions and wellbeing.

Contrary to these findings, Akkermans et al. (2009) found that young employees with lower educational levels experienced fewer job demands and less exhaustion at work. However, most studies thus far show a different picture. For example, Smulders (2005) argued that young workers with lower levels of education report higher levels of sickness absence and physical injuries at work, because of factors such as a high physical workload. Moreover, Van den Bossche (2004) demonstrated that these young workers are faced with more unwanted behaviors and intimidation. Other studies have underlined social class differences, in which lower classes (i.e. lower educational levels) generally report a less favorable work environment and more health-related problems (e.g. Upmark et al., 2001). These findings point to less favorable working conditions and more health risks for young employees with lower levels of education. Taken together, this leads us to formulate the following hypotheses:

H1. Young employees of lower educational levels experience lower levels of job resources and dedication compared with young employees of high educational level.

H2. Young employees of lower educational levels experience higher levels of job demands and emotional exhaustion compared with young employees of high educational level.

H3. Young employees of lower educational levels experience poorer health and perceived performance compared with young employees of high educational level. 
CDI

18,4

420
In the second part of our study, we investigated the longitudinal relationships between job characteristics, wellbeing, health, and performance of young employees with the JD-R model. This adds to the existing literature by providing new empirical insights in a sample of young employees. Further, as Boyd et al. (2011), and Hakanen et al. (2008) proposed, more longitudinal research concerning the relationships in the JD-R model is necessary. It is likely that the proposed relationships of the motivational and health impairment processes hold true for this sample of young employees with lower levels

of education, as earlier studies have demonstrated the robustness of these processes (e.g. Korunka et al., 2009). If these young workers experience unfavorable working conditions and poorly designed jobs, that will make them vulnerable to exhaustion and subsequent health problems (Bakker and Demerouti, 2007). Conversely, young employees have to learn and develop a lot in a relatively short period of time. Experiencing sufficient resources, such as autonomy and social support, may help them in becoming more motivated, and subsequently experience better health and performance (Bakker and Demerouti, 2007). Therefore, we formulated the following hypotheses:

H4a. Job resources have a positive association with dedication over time.

$H 4 b$. Dedication has a positive association with general health and perceived performance over time.

H5a. Job demands have a positive association with emotional exhaustion over time.

$H 5 b$. Emotional exhaustion has a negative association with general health and perceived performance over time.

We also investigated possible differences between the two educational groups with regard to the relationships (i.e. structural paths) in the JD-R model. Differences in the JD-R model between white collar workers and blue collar workers have been tested in earlier studies (e.g. Korunka et al., 2009; Toppinen-Tanner et al., 2002), but have not been demonstrated. However, initial cross-sectional support for differences between educational groups was demonstrated (Akkermans et al., 2009). Longitudinal research would be needed to further investigate this issue. In addition, studying these possible differences may tell us more about the unique characteristics of young employees and of specific educational groups. These findings would also add to our knowledge about the generalizability of the JD-R model. However, because differences have not been found and the robustness of the model has been demonstrated in various studies (e.g. Bakker et al., 2003b, 2007), we expected that this model would also hold in the case of young employees of different educational levels. That is, although we expected the actual level of the study variables to differ between educational groups, we did not expect differences regarding the motivational and health impairment processes across the groups:

H6. The relationships between the elements of the JD-R model will be consistent between educational groups.

Finally, in line with earlier findings from De Lange et al. (2008), we also examined potential reciprocal associations. De Lange et al. (2008) argued that a uni-directional view of work and mental health may be too narrow. They found that employees may 
be considered active shapers of their work environment, rather than just passive receivers. This idea is in line with the principles of COR theory (Hobfoll, 1989), which states that so-called gain cycles or loss cycles can develop over time. For example, Young and going Llorens et al. (2007) found that job resources, through efficacy beliefs, can influence work engagement, but that work engagement, in turn, can influence efficacy beliefs and job resources over time. De Lange et al. (2008) also stated that the nature of these reciprocal relationships is still unclear. To further investigate multi-directional associations, we tested potential reversed relationships between the study variables in our study.

\section{Method}

\section{Participants and procedure}

The data used in this study were derived from the two-wave Netherlands Working Conditions Cohort Study (NWCCS) (Koppes et al., 2011). The NWCCS is carried out annually by TNO Work and Employment, Statistics Netherlands, and the Dutch Ministry of Social Affairs and Employment. It constitutes a representative sample of the Dutch employees aged 15-64 years. Questionnaires were distributed in November 2008 (Time 1) and November 2009 (Time 2). A mixed-method design was used: individuals received a written questionnaire at their home address, which could be returned by mail or filled out online. A total of 10,395 employees completed the 2008 NWCS, of which 7,500 (72 percent) also responded to the follow-up questionnaire in 2009. In this study, we used a specific subset of young employees in the age range of 16-30 because our study was a follow-up of an earlier study (Akkermans et al., 2009). This previous study used an age criterion of 18-25 years, but we expanded the upper limit to 30 years in order to have a representative amount of employees with high educational levels. Following the advice of Taris and Kompier (2003), who argued that examining certain subgroups of employees in longitudinal designs may yield more meaningful information, we used subgroup analyses to investigate educational differences. This also corresponds to our overarching research goal of gaining a better understanding of young workers, specifically those with lower levels of education.

Only employees who filled out both questionnaires were used in the analyses: of the 1,650 young employees in 2008, 1,346 (82 percent) filled out the questionnaire again in 2009. There were 62 respondents who acquired a higher educational level at T2 or who reported that they had become self-employed or had stopped working: they were excluded from the analyses. These criteria resulted in a total sample size of 1,284 employees. We checked for selective attrition of participants between $\mathrm{T} 1$ and $\mathrm{T} 2$, but we did not find any significant differences with regard to gender $(F(1,1584)=1.16$, $p=0.22)$, educational level $(F(1,1585)=3.19, p=0.07)$, or age $(F(1,1580)=2.67$, $p=0.10)$.

The average age of the participants in the sample used for this study was 25.5 $(\mathrm{SD}=3.4$ years), and 63.4 percent were female. More than half of them had permanent employment (66.5 percent) and they worked an average of 32 hours per week $(\mathrm{SD}=9.8$ days). The most represented industries were trade (14.2 percent), general business (16.0 percent), and health and social work (25.5 percent). Participants were divided in two groups: lower educational level (less than 16 years of total education), and high educational level (more than 16 years of total education). Roughly speaking, this can be compared to non-college and college level in the North-American educational system. 
CDI

18,4

422

Criteria for placement in these groups followed the Dutch educational system. Employees with either no education, elementary education, lower secondary general education/pre-vocational education ("vmbo"), higher general secondary education ("havo"), pre-university education ("vwo"), or intermediate vocational education ("mbo") were placed in the lower educational group $(n=643)$. In this group, the job types that were represented most often were shop attendants, nurse assistants, and administrative work. Employees with higher vocational education ("hbo") or university level education ("wo") were placed in the high educational group $(n=641)$. The most represented job types in this group were teachers, technicians, and medical specialists. The two groups differed somewhat, but not significantly, with regard to gender (40 percent males in the lower educational group versus 33 percent males in the high educational group).

\section{Measurement instruments}

Job resources. Autonomy was measured with four items based on the job content questionnaire (JCQ) (Karasek, 1985; Karasek et al., 1998), which were translated to Dutch by Houtman et al. (1995). Items were measured on a three-point scale ranging from 1 (no) to 3 (yes, regularly). An example item was, "Can you decide how you perform your work?" $\left(\alpha_{\mathrm{T} 1}=0.78, \alpha_{\mathrm{T} 2}=0.76\right)$. Social support from the supervisor and from colleagues were both measured with four items based on the JCQ. Example items were "My supervisor takes the wellbeing of the employees into account" $\left(\alpha_{\mathrm{T} 1}=0.85\right.$, $\left.\alpha_{\mathrm{T} 2}=0.86\right)$, and "My colleagues show a personal interest in me" $\left(\alpha_{\mathrm{T} 1}=0.83\right.$, $\left.\alpha_{\mathrm{T} 2}=0.85\right)$, respectively. The items were measured on four-point scales, ranging from 1 (completely disagree) to 4 (completely agree).

Job demands. Work pressure was assessed with four items, based on the job content questionnaire (Karasek, 1985; Karasek et al., 1998). An example item was "Is your work hectic?" $\left(\alpha_{\mathrm{T} 1}=0.85, \alpha_{\mathrm{T} 2}=0.85\right)$. Emotional workload was measured with three items based on the copenhagen psychosocial questionnaire (Kristensen and Borg, 2000). An example item was "Is your work emotionally demanding?" $\left(\alpha_{T 1}=0.81, \alpha_{T 2}=0.81\right)$. Work pressure and emotional workload were both measured on a four-point scale, ranging from 1 (never) to 4 (always). Physical workload was measured with three items derived from the Integrated System of Social Surveys (POLS; Statistics Netherlands, 2003). Items were measured on a three-point scale ranging from 1 (no) to 3 (yes, regularly). An example item was, "Do you have to work in an uncomfortable position?" $\left(\alpha_{\mathrm{T} 1}=0.80, \alpha_{\mathrm{T} 2}=0.79\right)$.

Dedication, a subscale of work engagement, was measured with four items, based on the Utrecht work engagement scale (UWES) (Schaufeli and Bakker, 2003). The items were measured on a four-point scale, ranging from 1 (never) to 4 (always). A sample item was "My work inspires me" $\left(\alpha_{\mathrm{T} 1}=0.90, \alpha_{\mathrm{T} 2}=0.90\right)$. Emotional exhaustion, a subscale of burnout, was measured with five items, based on the Utrecht burnout scale (UBOS) (Schaufeli and Van Dierendonck, 2000). The items were measured on a seven-point scale, ranging from 1 (never) to 7 (every day). An example item was "I feel completely exhausted because of my work" $\left(\alpha_{\mathrm{T} 1}=0.83, \alpha_{\mathrm{T} 2}=0.86\right)$.

General health (i.e. perceived health) was measured with one item: "In general, how do you rate your own health?”. This item was derived from the Integrated System of Social Surveys (POLS; Statistics Netherlands, 2003). The item was measured on a five-point scale, ranging from 1 (bad) to 5 (excellent). A single item measure for 
self-rated health has been shown to have good predictive validity (Peterson et al., 2011). Perceived performance was measured with three items selected by the developers of the NWCCS, which were based on the questionnaire for task performance designed by Goodman and Svyantek (1999). The items were measured with a five-point scale, ranging from 1 (completely disagree) to 5 (completely agree). A sample item is, "I achieve the goals in my job" $\left(\alpha_{\mathrm{T} 1}=0.85, \alpha_{\mathrm{T} 2}=0.86\right)$.

Strategy of analysis

In part 1 of the analyses, we tested for differences between educational groups (i.e. low versus high) with repeated measures MANOVA followed by ANOVA. We used structural equation modeling (SEM) analyses with AMOS 20 (Arbuckle, 2011) to examine the fit of the data using the comparative fit index (CFI), the Tucker-Lewis index (TLI), and the root mean square error of approximation (RMSEA). CFI and TLI values of $>0.90$ and RMSEA values of $<0.08$ represent acceptable fit, whereas values of $>0.95$ and $<0.05$ represent a good fit (Hu and Bentler, 1999; Schumacker and Lomax, 2004). We performed the analyses with latent-variable structural path analyses with maximum likelihood estimation, and controlled for gender and age in our analyses. We could not control for job tenure as this was not assessed in the NWCCS. However, we did control for a change of employer and a change of job in the last 12 months in our analyses.

To test the models, we included the latent variables job resources (i.e. autonomy, social support from the supervisor, and social support from colleagues), job demands (i.e. work pressure, emotional workload, and physical workload), dedication, emotional exhaustion, general health, and task performance. To reduce the risk of common method variance, we tested the fit of a one-factor model where all indicators loaded onto one latent factor (Podsakoff et al., 2003). In addition, to ensure construct validity, we tested the fit of the measurement model, which consisted of all the indicators loading onto their proposed latent factors, and two competing models. In fitting the structural models, we followed the procedures advocated by De Lange et al. (2004). We compared four structural models: a stability model (containing only the synchronous correlations at $\mathrm{T} 1$ and the auto regression paths for each construct from T1 to T2), a causality model (adding all direct associations between $\mathrm{T} 1$ and $\mathrm{T} 2$ ), a reciprocal model (adding all reverse associations between $\mathrm{T} 1$ and $\mathrm{T} 2$ ), and a final model (deleting non-significant paths and optimizing model fit). Chi-square difference $\left(\Delta \chi^{2}\right)$ tests were used to compare successive models.

In part 2 of our analyses we used multiple group analysis using SEM. We examined differences between educational groups by examining whether an unconstrained model fitted the data better than several alternative models: a model in which the factor weights were constrained to be equal, a model in which the regression weights were constrained to be equal, and a model in which the means and intercepts were constrained to be equal.

\section{Results}

Intercorrelations of the study variables for the group with lower educational level are presented in Table I. Virtually all correlations were significant and in the expected direction. No extremely high correlations were found, indicating that multicollinearity is not likely to bias our results. We also performed a test for normality and outliers, but

\section{Young and going strong?}

423 
CDI

18,4

424

$\underline{ }$

\section{Table I.}

Intercorrelations of the study variables at $\mathrm{T} 1$ and T2 for group with lower educational level

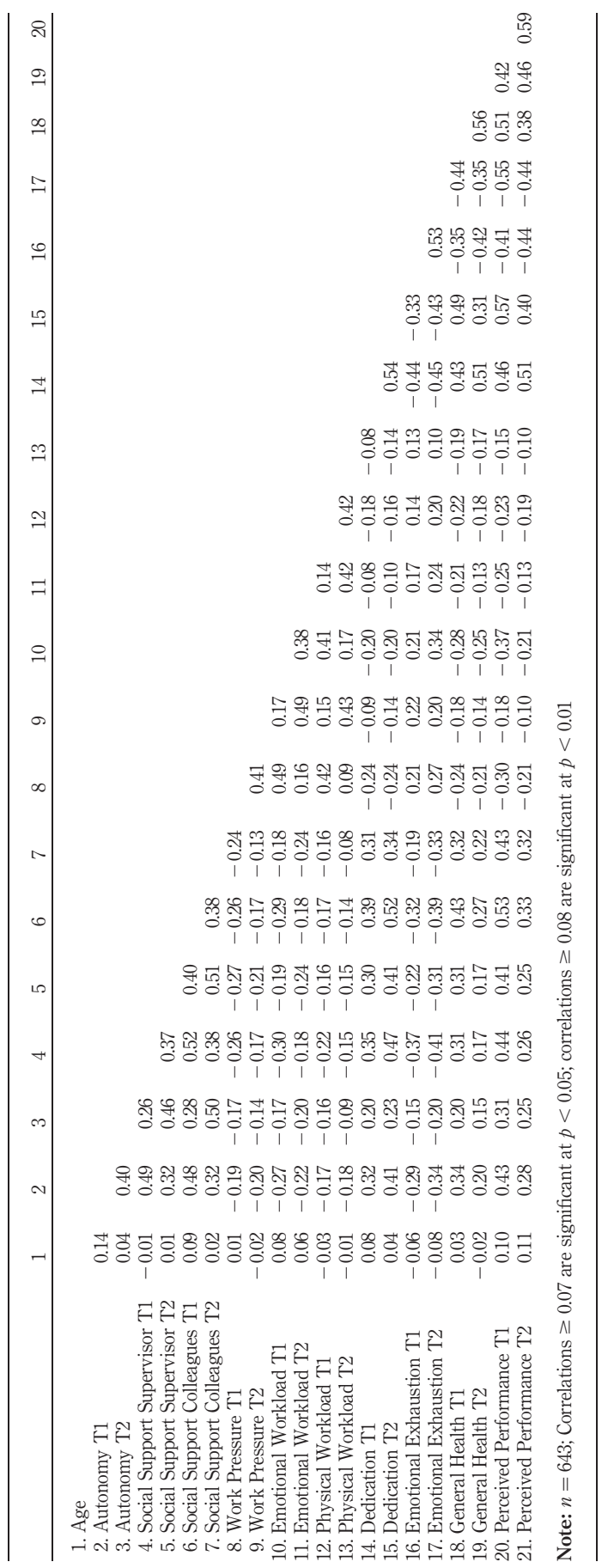


we did not find significant departure from normality or outliers. The correlation table for the group with high educational level can be obtained from the corresponding author.

\section{Young and going strong?}

\section{Part 1}

Mean differences between educational groups. The means and standard deviations are depicted in Table II. The group of low educational level scored significantly lower than the group with high educational level on autonomy at $\mathrm{T} 1(F(1,1282)=67.55$, $p<0.001)$, and T2 $(F(1,1282)=122.55, p<0.001)$, social support of the supervisor at $\mathrm{T} 1(F(1,1282)=42.60, p<0.001)$ and $\mathrm{T} 2(F(1,1282)=38.25, p<0.001)$, social support of colleagues at T1 $(F(1,1282)=9.09, p=0.003)$ and $\mathrm{T} 2(F(1,1282)=56.05$, $p<0.001)$, dedication at T1 $(F(1,1282)=25.18, p<0.001)$ and $\mathrm{T} 2(F(1,1282)=20.71$, $p<0.001)$, general health at T1 $(F(1,1282)=37.93, p<0.001)$ and $\mathrm{T} 2(F(1$, $1282)=86.95, p<0.001)$, and perceived performance at $\mathrm{T} 1(F(1,1282)=5.45$, $p=0.019)$ and $\mathrm{T} 2(F(1,1282)=35.17, p<0.001)$. In addition, they scored significantly higher on physical workload at T1 $(F(1,1282)=122.82, p<0.001)$ and T2 $(F(1$, $1282)=190.16, p<0.001)$, and on emotional exhaustion at $\mathrm{T} 1(F(1,1282)=68.32$, $p<0.001)$ and T2 $(F(1,1282)=14.98, p<0.001)$. No differences were found for work pressure and emotional workload. As hypothesized, young employees with lower educational level reported fewer job resources and less dedication (H1), more exhaustion (H2), and poorer health and perceived performance (H3). However, they did not experience more work pressure or emotional demands, only more physical demands, thereby partially supporting $H 2$.

Testing motivational and health impairment processes. The one-factor model showed a poor fit to the data: $\chi^{2}(170)=4,079.73, \quad p<0.01 ; \quad$ TLI $=0.54 ; \quad$ CFI $=0.58$; RMSEA $=0.13$, suggesting that common method variance was not a major issue in our study. To support the construct validity of our measures, we performed a confirmatory factor analysis in which we compared the measurement model with two competing models. The measurement model showed a good fit to the data: $\chi^{2}(108)=276.37, \quad p<0.01 ;$ TLI $=0.97 ; \quad \mathrm{CFI}=0.98 ; \mathrm{RMSEA}=0.04$. All factor loadings were significant onto their proposed factor with factor loadings ranging from

\begin{tabular}{lcccccccc}
\hline & \multicolumn{3}{c}{ Lower level $(n=643)$} & \multicolumn{3}{c}{ High level $(n=641)$} \\
& $M_{T 1}$ & $S D_{T 1}$ & $M_{T 2}$ & $S D_{T 2}$ & $M_{T 1}$ & $S D_{T 1}$ & $M_{T 2}$ & $S D_{T 2}$ \\
\hline Autonomy & 2.35 & 0.68 & 2.31 & 0.71 & $2.62^{*}$ & 0.54 & $2.69^{*}$ & 0.46 \\
Social support supervisor & 2.70 & 0.88 & 2.72 & 0.88 & $2.99^{*}$ & 0.75 & $3.00^{*}$ & 0.71 \\
Social support colleagues & 3.18 & 0.93 & 3.08 & 0.96 & $3.32^{*}$ & 0.71 & $3.42^{*}$ & 0.61 \\
Work pressure & 2.40 & 0.82 & 2.44 & 0.82 & 2.38 & 0.74 & 2.38 & 0.68 \\
Emotional workload & 1.98 & 0.99 & 2.02 & 0.98 & 1.93 & 0.77 & 1.95 & 0.77 \\
Physical workload & 2.00 & 0.72 & 2.03 & 0.76 & $1.57^{*}$ & 0.68 & $1.50^{*}$ & 0.62 \\
Dedication & 2.99 & 0.89 & 2.94 & 0.89 & $3.22^{*}$ & 0.75 & $3.15^{*}$ & 0.76 \\
Emotional exhaustion & 2.65 & 1.66 & 2.44 & 1.67 & $2.18^{*}$ & 1.12 & $2.10^{*}$ & 1.20 \\
General health & 3.33 & 1.04 & 3.27 & 1.07 & $3.65^{*}$ & 0.80 & $3.79^{*}$ & 0.91 \\
Perceived performance & 4.15 & 1.05 & 3.96 & 1.20 & $4.26^{*}$ & 0.54 & $4.28^{*}$ & 0.67
\end{tabular}

Notes: ${ }^{*} p<0.01$; Significance levels depict mean differences between the two educational groups within a measurement time

Table II.

Means and standard deviations of the study variables for lower educational level and for high educational level 
CDI

18,4

426

Table III.

Fit indices of multiple group models and of structural equation models for both educational groups, $N_{\text {low }}=643$ and $N_{\text {high }}=641$
0.61 to 0.76 . The first competing model, in which job resources and job demands were collapsed into one factor, showed significantly poorer fit to the data than the measurement model: $\Delta \chi^{2}(21)=1,489.02, \quad p<0.001 ; \quad$ TLI $=0.74 ; \quad C F I=0.83$; RMSEA $=0.10$. The second competing model, in which we collapsed job resources and dedication, and job demands and emotional exhaustion, also showed poorer fit to the data than the measurement model: $\Delta \chi^{2}(38)=3,417.67, \quad p<0.001 ;$ TLI $=0.51$; $\mathrm{CFI}=0.62 ; \mathrm{RMSEA}=0.14$. These results support the construct validity of our measures.

The results of the SEM analyses are shown in Table III. The first step was to fit the proposed JD-R model to the group of lower educational level. The initial stability model provided a bad fit to the data. Stability estimates ranged from 0.53 for job demands and emotional exhaustion to 0.71 for job resources. The stability model accounted for 29 percent of the variance in dedication, 26 percent in emotional exhaustion, 34 percent in general health, and 33 percent in task performance.

For the causality model, we added all direct paths from T1 to T2. Model fit was significantly increased compared to the stability model, $\Delta \chi^{2}(130)=482.21, p<0.001$, but the overall fit was unsatisfactory (see Table III). Next, we tested the reciprocal model. This again led to a significant increase in model fit compared to the causality model, $\Delta \chi^{2}(118)=60.73, p<0.001$, although the overall fit was still unsatisfactory. In the final step, we removed the non-significant direct and reversed paths, which provided another significant improvement to our model fit compared with the reciprocal model: $\Delta \chi^{2}(130)=204.62, p<0.001$. Our final model showed a good overall fit to the data: $\chi^{2}(130)=325.40, p<0.001$; TLI $=0.94$; CFI $=0.96$; RMSEA $=0.048$. The final model is depicted in Figure 1. It accounted for 51 percent of the variance in dedication, 45 percent in emotional exhaustion, 43 percent in general health, and 44 percent in perceived performance. $H 4 a, H 4 b, H 5 a$, and $H 5 b$ were confirmed for the group with lower educational level. We also tested this final model for the high education group (see Figure 2). Model fit was acceptable: $\chi^{2}(130)=391.77, p<0.001$; $\mathrm{TLI}=0.91 ; \mathrm{CFI}=0.94 ; \mathrm{RMSEA}=0.056$.

\begin{tabular}{lrccccc}
\hline Model & \multicolumn{1}{c}{$\chi^{2}$} & df & $\Delta \chi^{2}$ & TLI & CFI & RMSEA \\
\hline Unconstrained model & 654.13 & 258 & & 0.94 & 0.96 & 0.04 \\
Equal factor weights & 672.93 & 266 & $18.80^{*}$ & 0.94 & 0.96 & 0.04 \\
Equal regression weights & 722.28 & 274 & $68.15^{* *}$ & 0.93 & 0.95 & 0.04 \\
Equal means and intercepts & $1,185.30$ & 302 & $531.17^{* *}$ & 0.88 & 0.80 & 0.05 \\
Stability model L & $1,072.96$ & 142 & & 0.75 & 0.81 & 0.10 \\
Causality model L & 590.75 & 130 & $482.21^{* *}$ & 0.87 & 0.91 & 0.07 \\
Reciprocal model L & 530.02 & 118 & $60.73^{* *}$ & 0.87 & 0.92 & 0.07 \\
Final model L & 325.40 & 130 & $204.62^{* *}$ & 0.94 & 0.96 & 0.048 \\
Stability model H & $1,047.56$ & 142 & & 0.70 & 0.78 & 0.10 \\
Causality model H & 711.87 & 130 & $335.69^{* *}$ & 0.79 & 0.86 & 0.08 \\
Reciprocal model H & 691.18 & 118 & $20.69^{* *}$ & 0.77 & 0.86 & 0.09 \\
Final model H & 366.48 & 133 & $323.70^{* *}$ & 0.92 & 0.94 & 0.05
\end{tabular}

Notes: $\Delta \chi^{2}$ values in multiple group models represent comparisons with unconstrained model for equal factor weights, equal regression weights, and equal means and intercepts; $\mathrm{L}=$ participants with lower educational level; $\mathrm{H}=$ participants with high educational level; ${ }^{*} p<0.01 ;{ }^{*} p<0.01$ 


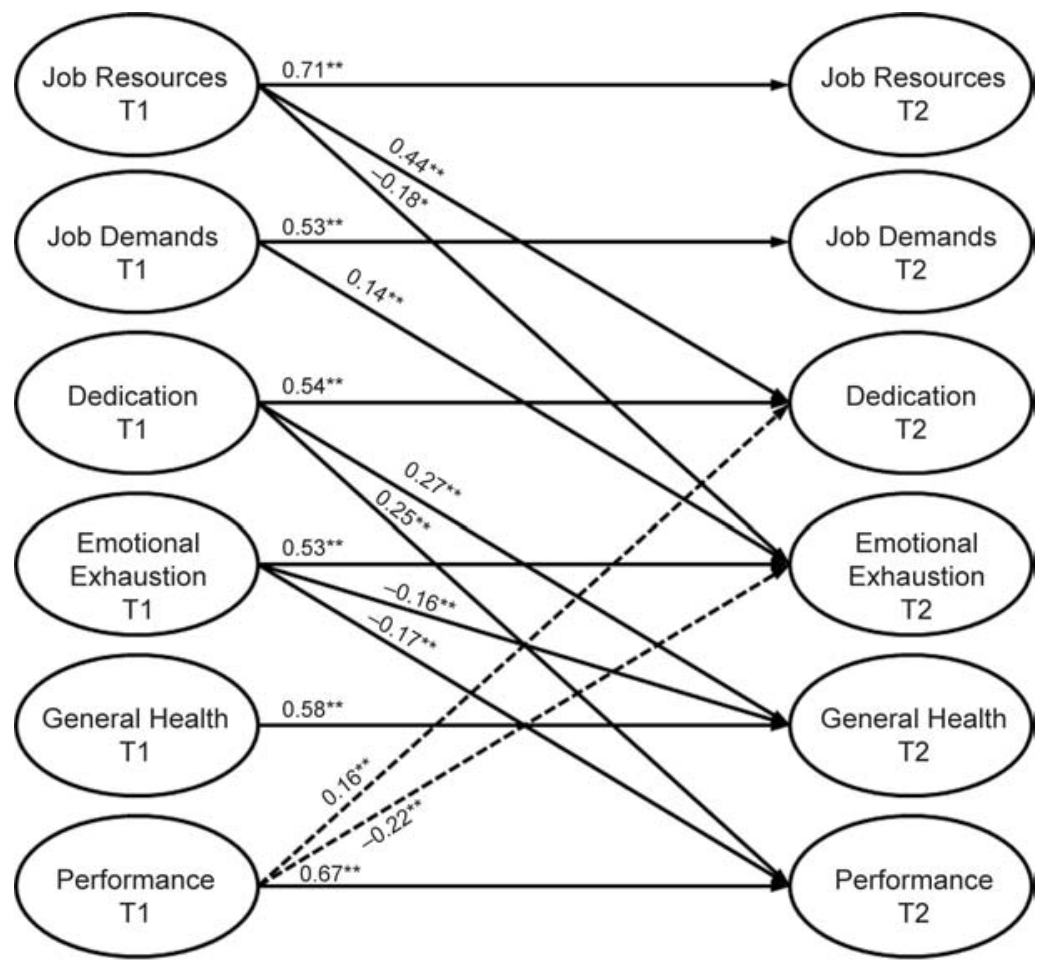

Notes: ${ }^{*} p<0.01 ;{ }^{* *} p<0.001 ; n=643$; dotted lines represent reversed effects

\section{Young and going strong?}

427
Figure 1. Final model for participants with lower educational level

Part 2

Differences between educational groups in the JD-R model. The results of the multiple group analyses are displayed in Table III. All three alternative models (i.e. a model with equal factor weights, a model with equal regression weights, and a model with equal means and intercepts) provided significantly worse model fit compared with the unconstrained model, indicating differences between the educational groups in factor weights $\left(\Delta \chi^{2}(266)=-18.80, p<0.001\right)$, structural paths $\left(\Delta \chi^{2}(274)=-68.15\right.$, $p<0.001)$, and means and intercepts $\left(\Delta \chi^{2}(302)=c 531.17, p<0.001\right)$. Because we had not expected any differences between the educational groups, we rejected $H 6$.

We examined which of the structural paths were different for the educational groups by performing a critical ratio for differences test. This is a test in which the parameters are tested across the groups with standardized Z-scores. Values of higher than 1.96 or lower than -1.96 indicate significant differences between groups. The results indicated that the parameters of job resources and perceived performance were more stable for the group with lower levels of education $(Z=-0.258$ and -2.81 , respectively), and that the relationship over time between job resources and emotional exhaustion $(Z=2.44)$, and between job demands and emotional exhaustion $(Z=1.96)$ were stronger for the group with higher levels of education. We also found differences between the groups for the reversed associations between perceived performance and 


\section{CDI}

18,4

\section{8}

Figure 2.

Final model for participants with high educational level

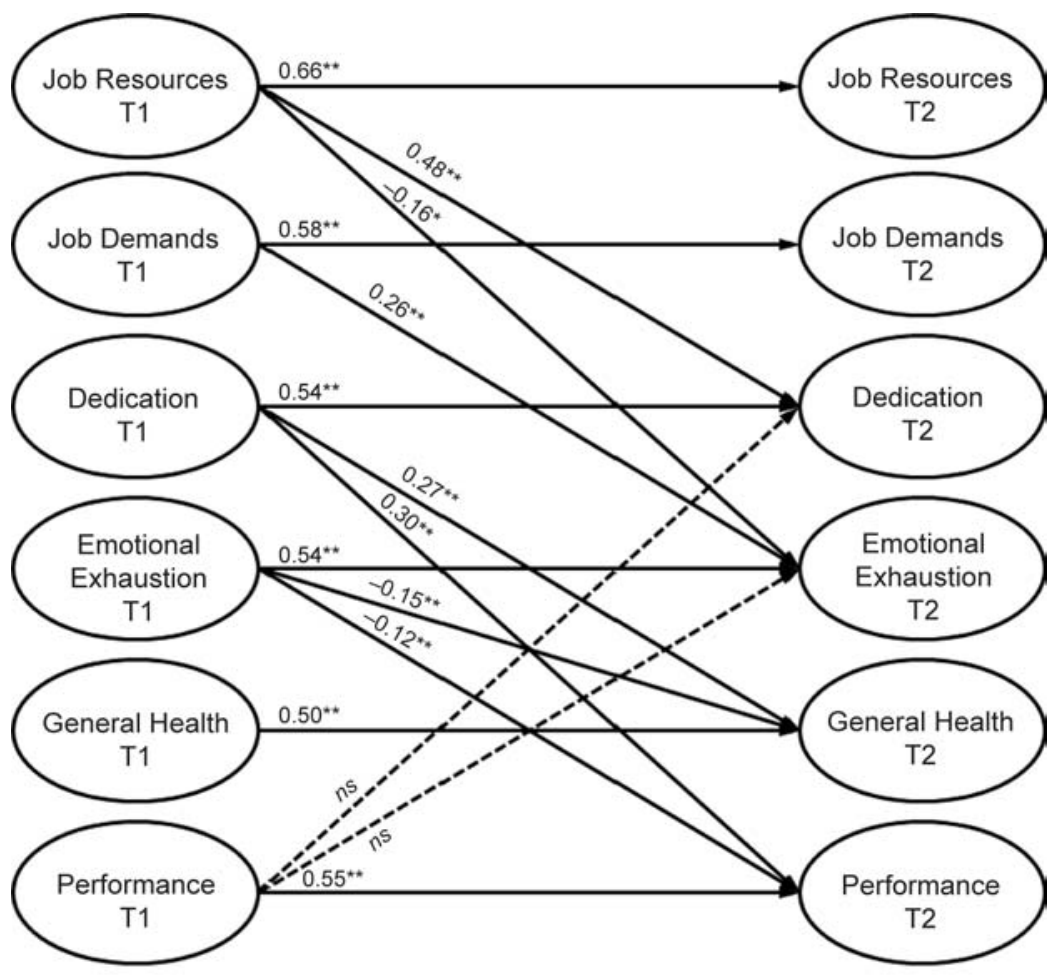

Notes: ${ }^{*} p<0.01 ;{ }^{* *} p<0.001 ; n=641$; dotted lines represent reversed effects

dedication $(Z=-2.40)$, and between perceived performance and emotional exhaustion $(Z=-3.60)$. These final two were only significant for the group with lower levels of education, as can also be seen in Figures 1 and 2.

\section{Discussion}

In this study, we investigated job characteristics, wellbeing, health, and performance of young employees in a large two-wave longitudinal sample of employees aged 16 to 30 years, representative of the Dutch workforce. In addition, we investigated potential differences between educational groups. Our results provide several new insights. First, we found differences between educational groups with regard to the levels of job characteristics (job resources and demands), wellbeing (dedication and emotional exhaustion), general health, and perceived performance. Second, we found longitudinal support for the motivational and health impairment processes of the job demands-resources (JD-R) model (Schaufeli and Bakker, 2004b) in our sample of young employees. Third, we demonstrated that differences exist between educational groups in the relationships of the JD-R model, indicating that the processes related to wellbeing, health, and performance are not the same for young employees of different educational levels. Below we will elaborate on each of these results. 
Differences between educational groups

We found differences in mean scores between the educational groups. As expected and in line with earlier studies (e.g. Adler and Ostrove, 1999; Akkermans et al., 2009), young employees with lower educational levels experienced fewer job resources, less dedication, more exhaustion, and poorer health and performance. They also experienced more physical demands. We did not find any differences in work pressure and emotional workload. These results differ from the results of a previous study (Akkermans et al., 2009), where young workers with lower levels of education actually experienced fewer job demands (i.e. work pressure, emotional workload, and mental workload). However, physical workload was not measured in that study, and was the only job demand in our study that showed a difference between educational groups. This is actually quite understandable considering that lower skilled jobs are usually more physically straining. Although lower skilled jobs are generally more routine based, it seems that the employees who perform these jobs do experience similar levels of job demands (and a higher physical workload) compared with higher skilled jobs. The results of our study emphasize the importance of gaining more knowledge about the role of job characteristics in the wellbeing, health, and performance of young employees with lower educational levels, because they seem to experience more physical demands, but fewer job resources compared with employees with high educational levels. This may also explain the higher ratings of emotional exhaustion and lower ratings of dedication, as they may not have sufficient job resources to deal with the demands in their work.

The motivational and health impairment processes for young employees

Support for the principles of the JD-R model has been demonstrated in several cross-sectional studies (e.g. Bakker et al., 2007; Schaufeli and Bakker, 2004b). However, longitudinal evidence has been scarce and conflicting (e.g. Hakanen et al., 2008; Mauno et al., 2007). Our results showed that - as expected - job resources were positively associated with dedication, and job demands were positively associated with emotional exhaustion over time. Moreover, and also as expected, dedication was positively related to health and performance, and emotional exhaustion was negatively related to health and performance over time. With these results, we provide longitudinal support for the motivational and health impairment processes of the JD-R model among young employees (e.g. Boyd et al., 2011; De Lange et al., 2008). Our findings show that autonomy, social support, work pressure, emotional workload, and physical workload may be related to future motivation and wellbeing of young employees. Moreover, the results show that dedication and emotional exhaustion may be related to future health and performance.

\section{Differences between educational groups in the JD-R model}

Contrary to our expectations, the educational groups differed in the relationships in the JD-R model. First, the health impairment process was weaker in the group with lower educational level. This result is in line with the findings in an earlier study (Akkermans et al., 2009) where motivational processes were more prominent among this group, as opposed to health impairment processes. Second, we found reciprocal relationships in our model between dedication and performance, and between exhaustion and performance, but only for the employees with lower educational level. This may reflect a gain cycle between dedication and performance, and a loss cycle between emotional exhaustion and

\section{Young and going strong?}

429 
CDI

18,4

430 performance for young employees with lower levels of education (De Lange et al., 2008). These findings would be in line with conservation of resources (COR) theory (Hobfoll, 1989). For these employees it may be particularly important to perceive themselves as competent in their work, as they are faced with little job security and extended job searches and stress (Nieuwenhuis et al., 2012). They may therefore need more confirmation than their colleagues with higher educational levels that they are performing well and that they can continue their jobs. Another possible explanation is that performing well may compensate for a lack of job resources by providing a sense of competence and positive emotions, which may serve as a buffer against exhaustion.

\section{Limitations and implications for future research}

A number of limitations and suggestions for future research need to be addressed. First, common method bias may have been a concern due to the exclusive use of self-report measures. Spector (2006) suggested this may not be a crucial problem in organizational research. Moreover, we used longitudinal data to reduce the risk of common method bias (Doty and Glick, 1998), and we tested a one-factor model (Podsakoff et al., 2003). However, it would be important to include ratings of supervisors and peers, and objective measures to further increase our knowledge about the role of job characteristics in predicting wellbeing, health, and performance of young employees.

Another limitation of our study concerns the indicators that we used for measuring motivation and strain. We could only use dedication and emotional exhaustion because the other indicators (vigor and absorption for engagement; depersonalization and reduced personal accomplishment for burnout) were not included in the NWCCS survey for reasons of economy. Although the indicators of work engagement are clearly correlated with each other, and the indicators of burnout are as well, future studies should also include the other dimensions to gain a more complete picture of motivation and strain among young workers.

A third limitation of our study is that we could not test a full mediation model due to our two-wave dataset (Taris and Kompier, 2006). Future research should use a three-wave dataset to test whether work engagement and burnout act as mediators in the motivational and health impairment processes of young employees with lower levels of education. In addition, it would be interesting to not only compare young workers of different educational levels with such a design, but also to include employees from different age categories. This could shed more light on differences between educational levels across age groups.

Our study also has a number of important strengths. First, we used a large sample of young employees that was representative of the Dutch workforce. Second, we specifically focused on educational differences between young employees. Third, we used two-wave longitudinal data for our analyses, which allowed us to examine both direct and reversed relationships between the elements of the JD-R model over time.

\section{Implications for theory}

Our study offers new insights into differences between young employees of different educational levels. In line with earlier studies (e.g. Adler and Ostrove, 1999; Akkermans et al., 2009) young employees with lower educational levels generally reported less favorable working conditions, and poorer wellbeing and performance. Our results show that the basic principles of the JD-R model (Demerouti et al., 2001) 
also hold for young employees with lower educational levels. Contrary to our expectations though, we did find differences between educational groups with regard to the relationships in the JD-R model, suggesting that the motivational and health impairment processes may differ across educational levels. Specifically, health impairment processes may be more prominent among employees with high educational levels, whereas stimulating motivational processes may be especially important for those with lower levels of education. Future research could specifically examine how those young workers with lower levels of education can be motivated, and how those with higher levels of education can be prevented from experiencing strain. Moreover, it would be interesting to study whether this also has an effect on outcome measures other than health and performance, for example their sickness absence.

We also found a reciprocal relationship between dedication and performance, and between emotional exhaustion and performance among individuals with lower levels of education. These findings indicate that there may be a gain cycle of performance in motivational processes, whereas there may be a loss cycle in health impairment processes. A sense of performing well may be especially important for these employees, possibly as a means of compensating their generally less favorable working conditions. These findings further support a multi-directional view of work and mental health (De Lange et al., 2008). Future studies should examine this issue in more detail, for example by studying the underlying psychological processes of these potential cycles among young employees with lower levels of education.

\section{Implications for practice}

An imbalance seems to exist for young employees with lower educational levels with regard to their job resources and demands, because they have fewer job resources at work, but more physical demands, compared with employees with a high level of education. These findings suggest that young employees with lower educational levels may be at risk for overcompensating at work (e.g. working harder or longer without having sufficient recovery from their efforts) because they have fewer resources to deal with demands compared with their higher educated counterparts. They are also more likely to experience less dedication, more exhaustion, and poorer health and performance, possibly because they generally work in a more cyclical and monotonous work environment. Therefore, it is crucial that HR policies and career counseling programs support this group of employees by creating more job resources, and by stimulating motivation and wellbeing during their first years of work. For example, they may appoint a mentor to their young employees who can provide support and guidance in managing the many new tasks and responsibilities.

This study also demonstrates the importance of self-perceived performance for young employees with lower levels of education. When these young workers feel that they are performing well, they subsequently become more dedicated and less exhausted. Because a sense of competence is so essential for this group, it is important that managers and HR consultants focus on this aspect by providing positive reinforcement and constructive feedback when supervising and supporting these young employees. Stimulating job resources, but also a sense of performing well, seems a fruitful combination of strategies to stimulate motivation and to reduce strain in young employees.

\section{Young and going strong?}

431 
CDI

18,4

432
Implications for society

Our findings demonstrate that differences exist between young individuals of varying educational levels with regard to job characteristics, work-related wellbeing, health, and performance. It is important to monitor these aspects and to intervene on these aspects in order to promote the occupational health and performance of these young employees. This is especially relevant because young employees have been struck hardest by the worldwide economic crisis, and because management of one's work and career is becoming ever more complex and challenging. Both research and practice may use the unique characteristics of each group to maintain a healthy and productive young workforce on the labor market.

\section{References}

Adler, N.E. and Ostrove, J.M. (1999), "Socioeconomic status and health: What we know and what we don't", Annals of the New York Academy of Sciences, Vol. 896, pp. 3-15.

Adler, N.E., Boyce, T., Chesney, M.A., Cohen, S., Folkman, S., Kahn, R.L. and Syme, S.L. (1994), "Socioeconomic status and health. The challenge of the gradient", American Psychologist, Vol. 49, pp. 15-24.

Akkermans, J., Brenninkmeijer, V., Blonk, R.W.B. and Koppes, L.L.J. (2009), "Fresh and healthy? Well-being, health and performance of young employees with intermediate education", Career Development International, Vol. 14, pp. 671-699.

Arbuckle, J.L. (2011), IBM SPSS AMOS 20 User's Guide, Amos Development Corporation, Springhouse, PA.

Bakker, A.B. and Demerouti, E. (2007), "The job demands-resources model: state of the art", Journal of Managerial Psychology, Vol. 22, pp. 309-328.

Bakker, A., Demerouti, E. and Schaufeli, W. (2003b), "Dual processes at work in a call centre: an application of the job demands-resources model", European Journal of Work and Organizational Psychology, Vol. 12, pp. 393-417.

Bakker, A.B., Demerouti, E., De Boer, E. and Schaufeli, W.B. (2003a), "Job demands and job resources as predictors of absence duration and frequency", Journal of Vocational Behavior, Vol. 62, pp. 341-356.

Bakker, A.B., Hakanen, J.J., Demerouti, E. and Xanthopoulou, D. (2007), "Job resources boost work engagement, particularly when job demands are high", Journal of Educational Psychology, Vol. 99, pp. 274-284.

Boyd, C.M., Bakker, A.B., Pignata, S., Winefield, A.H., Gillespie, N. and Stough, C. (2011), "A longitudinal test of the job demands-resources model among Australian university academics", Applied Psychology: An International Review, Vol. 60, pp. 112-140.

De Lange, A.H., De Witte, H. and Notelaers, G. (2008), "Should I stay or should I go? Examining the longitudinal relation between job resources and work engagement for stayers versus movers", Work \& Stress, Vol. 22, pp. 201-233.

De Lange, A.H., Taris, T.W., Kompier, M.A.J., Houtman, I.L.D. and Bongers, P.M. (2004), "The relationship between work characteristics and mental health: Examining normal, reversed and reciprocal relationships in a 4-wave study", Work \& Stress, Vol. 18, pp. 149-166.

Demerouti, E., Bakker, A.B., Nachreiner, F. and Schaufeli, W.B. (2001), "The job demands-resources model of burnout”, Journal of Applied Psychology, Vol. 85, pp. 499-512.

Doty, D. and Glick, W. (1998), "Common method bias: does common methods variance really bias results?", Organizational Research Methods, Vol. 1, pp. 374-406.

Elfering, A., Semmer, N.K., Tschan, F., Kälin, W. and Bucher, A. (2007), "First years in job: a three-wave analysis of work experiences", Journal of Vocational Behavior, Vol. 70, pp. 97-115. 
European Commission (2012), Employment and Social Developments in Europe 2011, Young and going Publications Office of the European Union, Luxembourg.

González-Roma, V., Schaufeli, W.B., Bakker, A.B. and Llorens, S. (2006), "Burnout and work strong? engagement: independent factors or opposite poles?", Journal of Vocational Behavior, Vol. 68, pp. 165-174.

Goodman, S.A. and Svyantek, D.J. (1999), "Person-organization fit and contextual performance: do shared values matter", Journal of Vocational Behavior, Vol. 55, pp. 254-275.

Goodwin, J. and O'Connor, H. (2007), “Continuity and change in the experiences of transition from school to work", International Journal of Lifelong Learning, Vol. 26, pp. 555-572.

Hakanen, J.J., Schaufeli, W.B. and Ahola, K. (2008), "The job demands-resources model: a three-year cross-lagged study of burnout, depression, commitment, and work engagement”, Work \& Stress, Vol. 22, pp. 224-241.

Hobfoll, S.E. (1989), "Conservation of resources, a new attempt at conceptualizing Stress", American Psychologist, Vol. 44, pp. 513-524.

Houtman, I.L.D., Goudswaard, A., Dhondt, S., Van der Grinten, M., Hildebrand, V., Kompier, M. and Kompier, M. (1995), Evaluatie van de monitorstudie naar stress en lichamelijke belasting ("Evaluation of the Monitor for Stress and Physical Strain”), VUGA, Den Haag.

Hu, L. and Bentler, P.M. (1999), "Cutoff criteria for fit indexes in covariance structure analysis: conventional criteria versus new alternatives", Structural Equation Modeling, Vol. 1, pp. 1-55.

Karasek, R., Brisson, C., Kawakami, N., Houtman, I., Bongers, P. and Amick, B. (1998), "The job content questionnaire (JCQ): an instrument for internationally comparative assessments of psychosocial job characteristics", Journal of Occupational Health Psychology, Vol. 3, pp. 322-355.

Karasek, R.A. (1985), Job Content Questionnaire and User's Guide, Department of Work Environment, University of Massachusetts, Lowell.

Koivisto, P., Vuori, J. and Nykiri, E. (2007), "Effects of the school-to-work group method among young people", Journal of Vocational Behavior, Vol. 70, pp. 277-296.

Koppes, L.L.J., De Vroome, E.M.M. and Van den Bossche, S.N.J. (2011), The Netherlands Working Conditions Cohort Study, TNO, Hoofddorp.

Korunka, C., Kubicek, B., Schaufeli, W.B. and Hoonakker, P. (2009), "Work engagement and burnout: testing the robustness of the job-demands resources model", The Journal of Positive Psychology, Vol. 4, pp. 243-255.

Kristensen, T. and Borg, V. (2000), Copenhagen Psychosocial Questionnaire (COPSOQ), National Institute of Occupational Health, Copenhagen.

Kuijpers, M.A.C.T. and Meijers, F. (2012), "Learning for now or later? Career competencies among students in higher vocational education in The Netherlands", Studies in Higher Education, Vol. 37, pp. 449-467.

Llorens, S., Schaufeli, W., Bakker, A. and Salanova, M. (2007), "Does a positive gain spiral of resources, efficacy beliefs, and engagement exist?", Computers in Human Behavior, Vol. 23, pp. 825-841.

Mauno, S., Kinnunen, U. and Ruokolainen, M. (2007), "Job demands and resources as antecedents of work engagement: a longitudinal study", Journal of Vocational Behavior, Vol. 70, pp. 149-171.

Nieuwenhuis, L., Coenen, J., Fouarge, D., Harms, T. and Oosterling, M. (2012), "De creatie van publieke waarde in het middelbaar beroepsonderwijs" ("The creation of public value in intermediate vocational education”), available at: www.nwo.nl/files.nsf/pages/NWOP_ 8YRECJ/\$file/PubliekewaardevanhetMBO.pdf 
CDI

18,4

434
Peterson, U., Bergström, G., Demerouti, E., Gustavsson, P., Asberg, M. and Nygren, A. (2011), "Burnout levels and self-rated health prospectively predict future long-term sickness absence: a study among female health professionals", Journal of Occupational and Environmental Medicine, Vol. 53, pp. 788-793.

Podsakoff, P.M., MacKenzie, S.B., Lee, J. and Podsakoff, N.P. (2003), "Common method biases in behavioral research: a critical review of the literature and the recommended remedies", Journal of Applied Psychology, Vol. 88, pp. 879-903.

Raad voor Werk en Inkomen (2009), Raad voor Werk en Inkomen Arbeidsmarktanalyse 2009 (Analysis of the Labor Market 2009), Raad voor Werk en Inkomen, The Hague.

Raad voor Werk en Inkomen (2010), Arbeidsmarktanalyse 2010 (Analysis of the Labor Market 2010), Raad voor Werk en Inkomen, The Hague.

Ryan, P. (2001), "The school-to-work transition: a cross-national perspective", Journal of Economic Literature, Vol. 39, pp. 34-92.

Savickas, M.L. (1998), "The transition from school to work: a developmental perspective”, Career Development Quarterly, Vol. 47, pp. 326-336.

Schaufeli, W.B. and Bakker, A.B. (2003), Voorlopige handleiding Utrechtse Bevlogenheidsschaal (UBES), Universiteit Utrecht: sectie Psychologie van Arbeid, Gezondheid en Organisatie.

Schaufeli, W.B. and Bakker, A.B. (2004a), "Bevlogenheid: een begrip gemeten ('Work Engagement: Measuring a Concept')", Gedrag \& Organisatie, Vol. 17, pp. 89-112.

Schaufeli, W.B. and Bakker, A.B. (2004b), "Job demands, job resources, and their relationship with burnout and engagement", Journal of Organizational Behavior, Vol. 25, pp. 293-325.

Schaufeli, W.B. and Taris, T.W. (2005), "The conceptualization and measurement of burnout: common grounds and words apart", Work \& Stress, Vol. 19, pp. 256-262.

Schaufeli, W.B. and Van Dierendonck, D. (2000), Handleiding van de Utrechtse Burnout Schaal (UBOS), Swets \& Zeitlinger, Lisse.

Schaufeli, W.B., Salanova, M., González-Roma, V. and Bakker, A.B. (2002), "The measurement of engagement and burnout: a two sample confirmatory factor analytic approach", The Journal of Happiness Studies, Vol. 3, pp. 71-92.

Schumacker, R. and Lomax, R. (2004), A Beginner's Guide to Structural Equation Modeling, 2nd Ed., Lawrence Erlbaum Associates, Mahwah, NJ.

Smulders, P.G.W. (2005), Jongere en oudere werknemers: hun werk, werktijden, ongevallen en verzuim (Younger and Older Employees: Their Work, Work Schedules, Accidents, and Absence), TNO, Hoofddorp.

Spector, P.E. (2006), "Method variance in organizational research", Organizational Research Methods, Vol. 9, pp. 221-232.

Statistics Netherlands (2003), Permanent Onderzoek Leefsituatie (POLS) Gezondheid 2004 (Integrated System of Social Surveys 2004), Centraal Bureau voor de Statistiek, Heerlen.

Taris, T. and Kompier, M. (2003), "Challenges in longitudinal designs in occupational health psychology”, Scandinavian Journal of Work, Environment and Health, Vol. 29, pp. 1-4.

Taris, T. and Kompier, M. (2006), "Games researchers play - extreme Group analysis and mediation analysis in longitudinal occupational health psychology", Scandinavian Journal of Work, Environment and Health, Vol. 32, pp. 463-472.

Toppinen-Tanner, S., Kalimo, R. and Mutanen, P. (2002), "The process of burnout in white-collar and blue-collar jobs: eight-year prospective study of exhaustion", Journal of Organizational Behavior, Vol. 23, pp. 555-570.

Upmark, M., Lundberg, I., Sadigh, J. and Bigert, C. (2001), "Conditions during childhood and adolescence as explanations of social class differences in disability pension among young men”, Scandinavian Journal of Public Health, Vol. 29, pp. 96-103. 
Van den Bossche, S.N.J. (2004), Intimidatie en geweld op het werk (Intimidation and Violence at Work), TNO, Hoofddorp.

Van der Heijden, B.I.J.M., De Lange, A.H., Demerouti, E. and Van der Heijde, C.M. (2009), "Age Young and going strong? effects on the employability-career success relationship", Journal of Vocational Behavior, Vol. 74, pp. 156-164.

\section{About the authors}

435

Jos Akkermans works as a researcher of education at HAN University of Applied Sciences, The Netherlands. His $\mathrm{PhD}$ and his research are in Work and Organizational Psychology, and he mainly focuses on career development, workplace learning, employability, and well-being of young employees. Jos has developed and empirically tested the CareerSKILLS program, and he has developed and validated the Career Competencies Questionnaire. Jos Akkermans is the corresponding author and can be contacted at: jos.akkermans@han.nl

Veerle Brenninkmeijer is working as an Assistant Professor at Utrecht University, Department of Social and Organizational Psychology, The Netherlands. She conducts research in the broad field of Work and Organizational Psychology, covering issues like well-being and performance in the work situation, career development of young professionals, and reintegration of employees with mental health complaints. In her former job, Veerle worked as a researcher/consultant for The Netherlands Association for Applied Scientific Research (TNO). In this job she focused on long-term sickness absence, reintegration and activation of the unemployed. She wrote her $\mathrm{PhD}$. thesis at the University of Groningen on social comparison and burnout.

Seth N.J. van den Bossche MSc, PhDc, Occupational and Organizational Psychologist, is Senior Research Scientist at TNO Work and Employment. He has extended experience with large scale quantitative research related to the quality of working life, both on a national and international level. Most of his work at TNO is related to the monitoring of occupational safety and health in The Netherlands. He developed and coordinated The Netherlands Working Conditions Survey, a large scale survey among Dutch employees. Currently he is in charge of the Work and Employment Surveillance program, consisting of several surveys and cohort-studies among employers and employees, and several related research projects. Finally, he is working on a $\mathrm{PhD}$ thesis on workplace violence and harassment and is peer reviewer for several journals on occupational health.

Professor Dr Roland W.B. Blonk is educated in clinical psychology at the University of Amsterdam, The Netherlands and received his $\mathrm{PhD}$ on treatment outcome studies. Currently he is employed at TNO Work and Employment, one of the largest applied research centers in Europe. He holds a special chair at the University of Utrecht on two research topics: work related psychological complaints and return to work and social inclusion and employability. Besides team manager at TNO he is program manager of two large research programs on these issues.

Wilmar B. Schaufeli is full Professor of Work and Organizational Psychology at Utrecht University, The Netherlands, and Visiting Professor at Loughborough Business School, UK, and Jaume I Universitat, Castellon, Spain. He has published almost 400 articles, chapters and books, mainly on occupational health psychology (see: www.schaufeli.com). Dr Schaufeli is a fellow of the European Academy of Occupational Health Psychology, a licensed occupational health psychologist, and also works part-time as an organizational consultant.

To purchase reprints of this article please e-mail: reprints@emeraldinsight.com Or visit our web site for further details: www.emeraldinsight.com/reprints 